\title{
Laboratory Wear Tests With Automotive Gear Lubricants
}

\author{
By Samuel A. McKee, James F. Swindells, Hobart S. White, and Wayne Mountjoy
}

\begin{abstract}
In the past, most of the work with the SAE extreme-pressure lubricants testing machine has been confined to the testing of the load-carrying capacity of gear lubricants under certain fixed operating conditions that simulate high speed and shock load. This paper describes a different use of the machine for the determination of the wear with gear lubricants under conditions simulating high torque and low speed. The modifications to the machine and the procedure used are described in detail.

Data were obtained with a straight mineral oil and 11 representative samples of commercial lubricants commonly used in automotive gears, when operating at $225^{\circ} \mathrm{F}$ and various constant loads. The loads covered were 90, 135, 180, and 225 pounds (scale reading). These data showed marked differences in the performance of the lubricants in the higher load range. The trends shown by these differences were in reasonable agreement with the known service performance of these lubricants.

Other information given includes an indication of run-in wear, the change in surface roughness of the test cups with wear, and the effect of the original surface roughness on the rate of wear.
\end{abstract}

\section{Introduction}

Of the various laboratory testing machines that have been commonly used in the study of automotive gear lubricants, the SAE machine, in general, more nearly simulates gear operation. ${ }^{12}$ The two contacting cylindrical test cups of this machine are rotated at different speeds under load and provide a combined rubbing and rolling action that is typical of loaded gear teeth. A further similarity is a line contact that is constantly changing with respect to the surfaces of both cups, hence no one point on the periphery is under continuous stress.

In the past, most of the work with the SAE machine has been confined to the testing of the loadcarrying capacity of gear lubricants under certain fixed operating conditions that simulate shock loading. ${ }^{3}$ This paper describes the use of the

1 William S. James, SAE Trans. 4\%, 312 (1940).

${ }_{2}$ S. A. McKee, F. G. Bitner, and T. R. McKee, SAE Trans. 33, 402 (1933).

${ }^{3}$ CRC Test procedure (CRC designation L-17-545), CRC Handbook, p. 458 (1946). machine for the determination of the wear with gear lubricants under conditions simulating high torque and low speed.

The machine is particularly adaptable for wear tests in that the test specimens are of such size and shape that accurate indications of wear may be obtained by determinations of loss in weight. Also, any wear that occurs on the test cups does not materially affect the area of contact under a given load. On the other hand, the method of lubricating the test surfaces is not especially suitable for long-time tests, and it seemed advisable to modify the machine in this respect.

\section{Modifications of the SAE Machine}

Although the primary objective in modifying the lubricating system was long-time operation, it was felt desirable also to provide better temperature control of the upper test cup. The lower test cup is supported in a small oil box with the oil level about half way up the cup, and lubrication 
between the two cups is effected by the oil carried up by the lower cup as it rotates. Since only the lower cup is cooled by immersion in the oil bath, the upper cup runs at a considerably higher temperature. This is usually quite noticeable in the load-carrying capacity tests. For this reason, it was decided to use an additional oil reservoir of larger capacity with a circulating system for applying a stream of oil to the upper test cup.

The design of the SAE machine is such that one of the major problems in the development of an oil circulating system was the prevention of excessive oil leakage around the test cups and oil box. The system in present use is reasonably satisfactory in this respect.

The arrangement of this circulating system is shown in figure 1. The oil being tested is drawn from the reservoir, A, by the motor-driven pump, $\mathrm{B}$, and delivered through the $1 / 4-\mathrm{in}$. pipe, C, to the top of the upper test cup, which is covered by the special oil splash guard, D. The oil then drains to the oil box, $\mathrm{E}$. This box is fitted with two $\frac{1}{4}-\mathrm{in}$. overflow pipes, $\mathrm{F}$, so located that the oil level in the box partially immerses the lower test cup. The oil from the overflows falls into open fittings in the $3 / 4-$ in. drain pipe, $G$, and drains back to the reservoir. Also, shown in the figure are thermo-

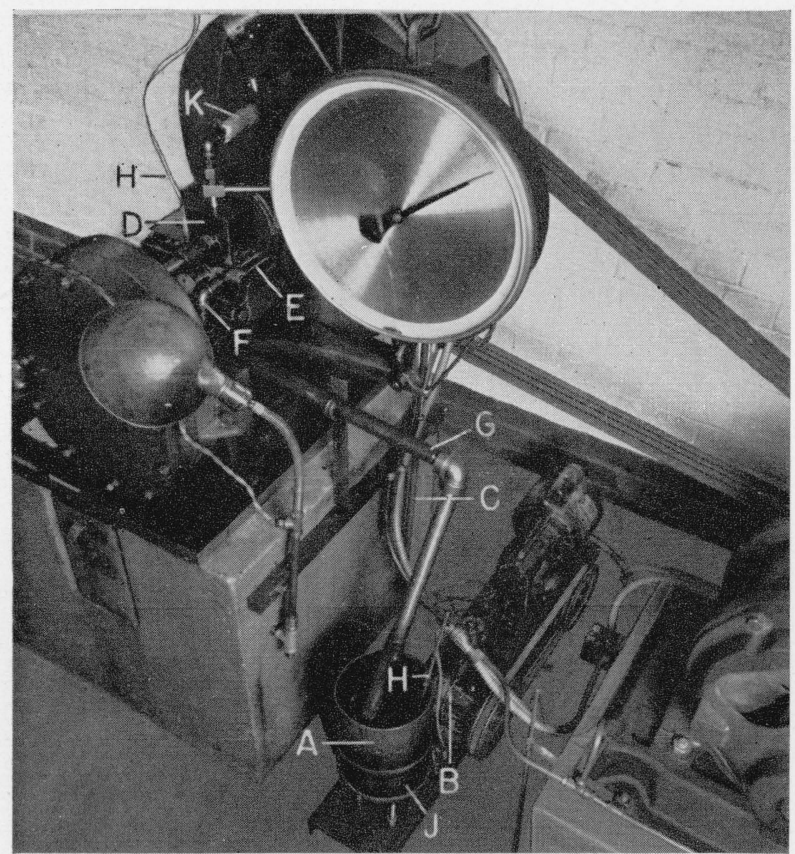

FIgURE 1. General view of SAE machine, showing arrangement of special oil-circulating system. couples, $\mathrm{H}$, in the oil box and oil reservoir, heater, $\mathrm{J}$, on the oil reservoir, and auxiliary heater, K, on the delivery pipe.

A view of the test cups and oil box assembled except for the splash guards is shown in figure 2 . The counterweight, $\mathrm{L}$, is mounted from the oil box to counterbalance the overflow pipes and the overhanging lower test-cup shaft. An oil thrower, $\mathrm{M}$, is mounted on the upper test shaft as shown, and $\mathrm{N}$ is a special nut for the upper test cup (a portion of its length is a cylindrical seat for the inner oil guard, which is shown in fig. 3). Figure 3 shows accessory parts and changes in the oil box as follows: $\mathrm{P}$, inner oil guard that rides on upper test shaft; $\mathrm{R}$, plate sealing oil-box bearing; $\mathrm{S}$ seal for shaft at other oil-box bearing; T, dams welded to

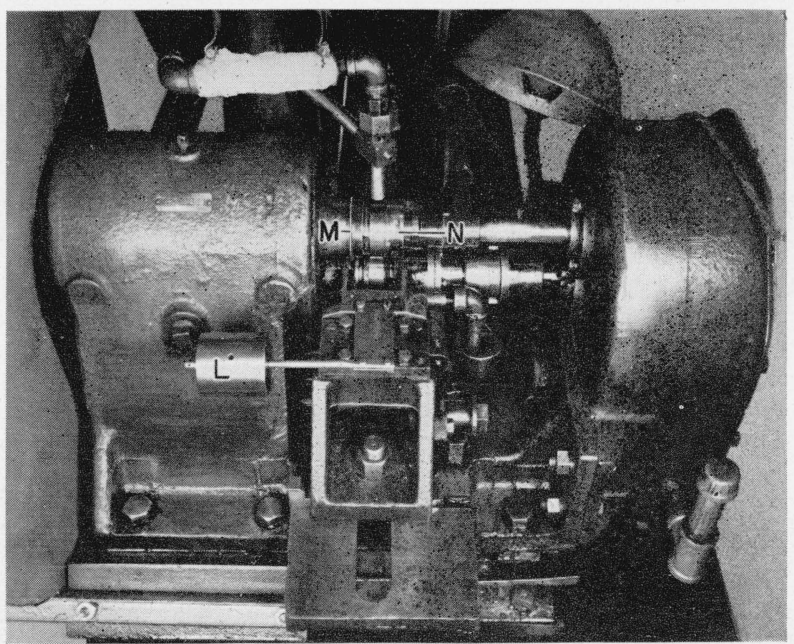

Figure 2. Close-up view of test shafts and oil-box assembly of SAE machine.

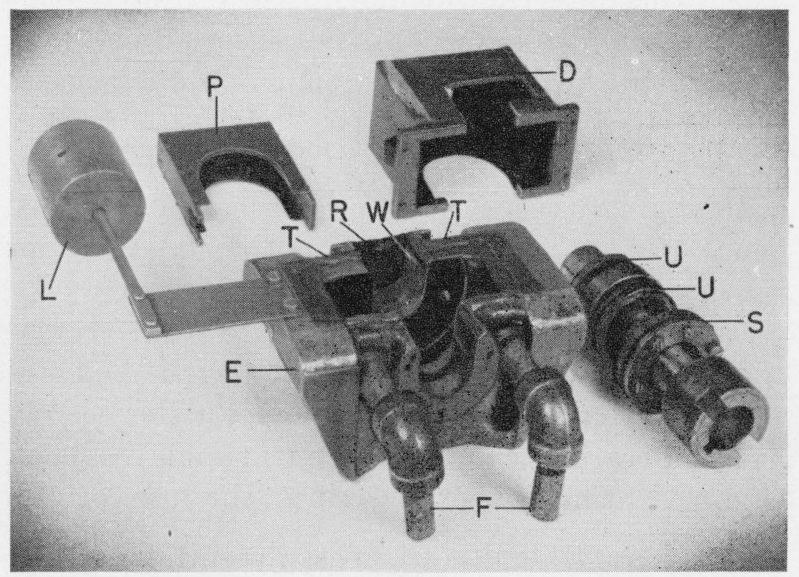

FIgure 3. Special parts and changes to oil box and lower test shaft. 
oil box to fit outer oil guard D; U, grooves in spacers on lower test shaft; W, special drain hole in oil-box bearings.

\section{Lubricants}

The lubricants used in these tests included a Navy Contract 1080 mineral oil, five lubricants conforming to U. S. Army Specification $2-105 \mathrm{~B},{ }^{4}$ five lubricants conforming to Federal Specification $\mathrm{VV}-\mathrm{L}-761,{ }^{5}$ and one lead-soap active-sulfur lubricant. All were SAE 90 grade. In the figures given in this paper the mineral oil is designated by the number 1080, the Army spec:fication lubricants by the letter $A$ and a number representing a particular lubricant, the Federal specification lubricants by the letter $\mathrm{F}$ and the lubricant number, and the lead-soap active-sulfur lubricant by the letters AS.

\section{Test Method}

In all the tests, the upper test cup was driven at a speed of $500 \mathrm{rpm}$ with a 3.4 to 1 gear ratio between the upper and lower cups. This provided a 2.4 to 1 ratio of rubbing to rolling at the contacting surfaces. The specimens used were steel Timken test cups $\mathrm{T}-48651$ and in most of the tests had an average surface roughness of from 25 to 30 microinches (rms, Profilometer). A 2-quart sample of oil was used in each run. This was circulated at a rate of about $500 \mathrm{~g} / \mathrm{min}$. With a constant oil temperature of $225^{\circ} \mathrm{F}$, tests were made at constant loads of $90,135,180$, and $225 \mathrm{lb}$ (scale readings), respectively. The loading system is such that the corresponding loads on the 2 -in. diameter by $1 / 2$-in. test cups are ten times the scale readings. Tests were also made at $250^{\circ} \mathrm{F}$ and 180-lb load. The above conditions approximate the range of conditions covered in the usual high-torque low-speed gear tests.

The test cups were weighed before and after each period of operation during a test, the loss in weight being used as a measure of wear during the period. In the first few tests in the program, weighings were made at frequent intervals, and the tests were run for as long as $75 \mathrm{hr}$. It was found, however, that representative data could be

\footnotetext{
${ }^{4}$ U. S. Army Specification No. 2-105B, Lubricant, Gear, Universal (Mar. $28,1946)$.

${ }^{3}$ Federal speciflcation VV-L-761 for Lubricants, Enclosed-gear, HypoidGear, and other types (Nov. 28, 1947).
}

obtained by operating for about $25 \mathrm{hr}$, making weighings after operating 4, 11, 18, and $25 \mathrm{hr}$, respectively. Most of the tests were run on this schedule.

\section{Wear Data}

Data obtained in the tests with the mineral oil, lead-soap active-sulfur lubricant and five Army specification 2-105B lubricants, operating at $90-1 \mathrm{~b}$ load (scale reading) and at a temperature of $225^{\circ}$ $\mathrm{F}$ are shown in figure 4 , where the loss in weight of both test cups expressed in milligrams is plotted against time in hours. These data indicate that under the conditions present there was a run-in period of high rate of wear for a few hours, after which the wear settled down to a fairly constant rate. In general, this straight portion of the curve is well established by $25 \mathrm{hr}$ of operation, and subsequent test runs were of that duration.

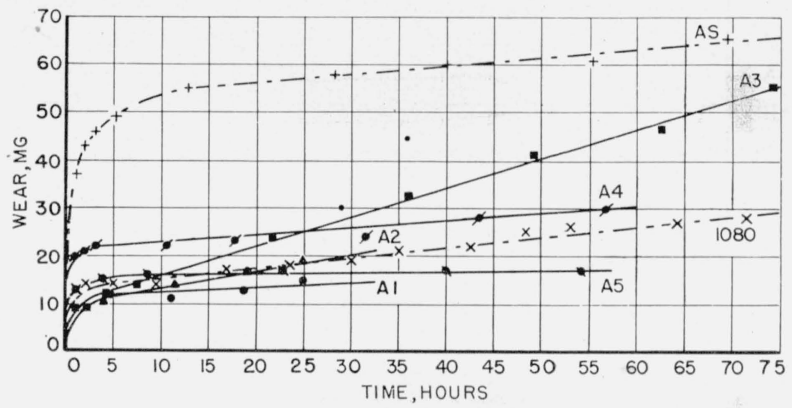

Figure 4. Wear versus time curves for Army specification 2-105 B lubricants operating at 90-lb load and $225^{\circ} \mathrm{F}$.

Wear versus time curves obtained under similar conditions with five Federal Specification VV-L761 lubricants are given in figure 5. These curves are like those in figure 4 in that they show that there is a run-in period followed by a region where there is a constant rate of wear. The slope of this straight portion of the curve is more significant from the standpoint of estimating gear life than the observed loss in weight for any given length of time. This is illustrated by a comparison of curves 1080, F2, and F5 in figure 5. With these lubricants the losses in weight are quite different, but the slopes of the curves are about alike. Accordingly, if they were extrapolated to estimate long-time wear, the initial differences in loss in weight would lose their significance.

Similar curves for all the lubricants when operating at $225^{\circ} \mathrm{F}$ and under loads of 135,180 , and $225 \mathrm{lb}$ are given in figures 6,7 , and 8 ; re- 


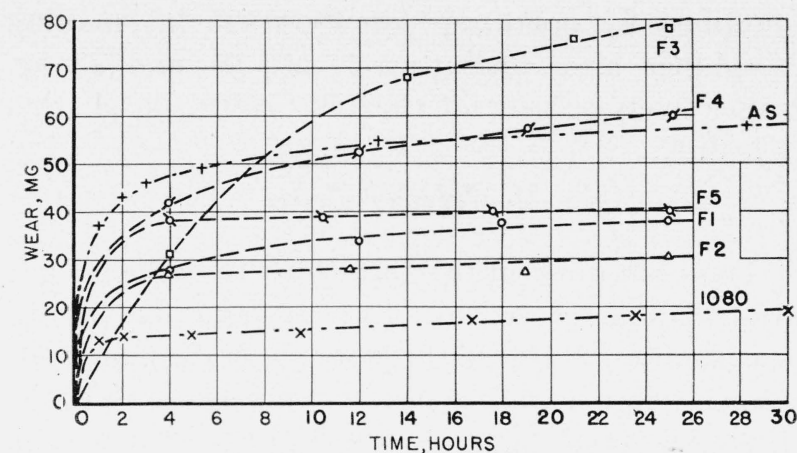

Figure 5. Wear versus time curves for Federal Specification $V V-L-761$ lubricants operating at 90-lb load and $225^{\circ} \mathrm{F}$.

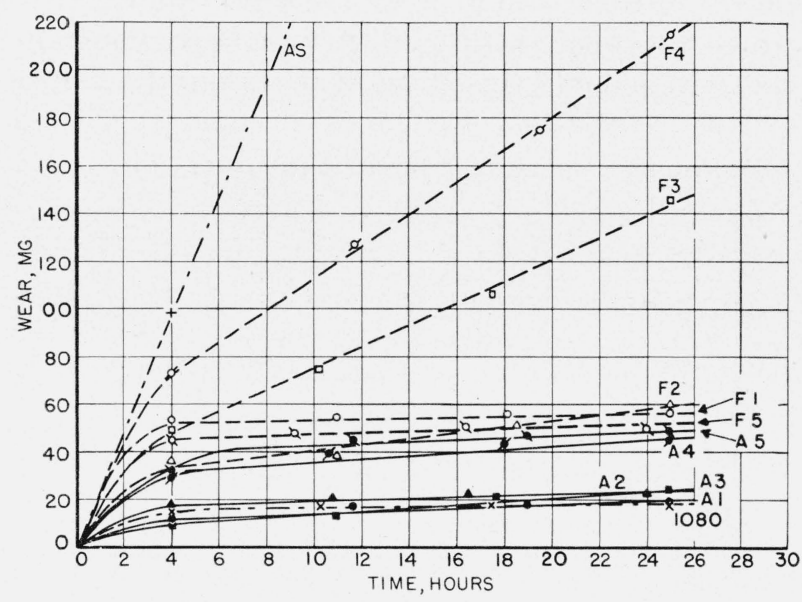

FIGURE 6. Wear versus time curves for all lubricants operating at $135-\mathrm{lb}$ load and $225^{\circ} \mathrm{F}$.

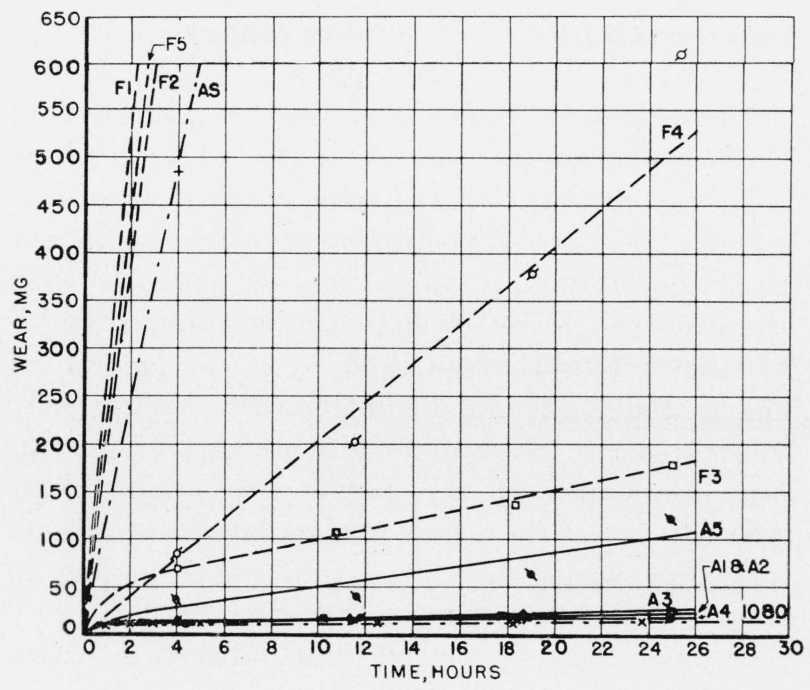

Figure 7. Wear versus time curves for all lubricants operating at $180-\mathrm{lb}$ load and $225^{\circ} \mathrm{F}$. spectively. From these figures, it will be noted that at the higher loads the rate of wear with some of the lubricants showed a marked increase, whereas with others there was little effect.

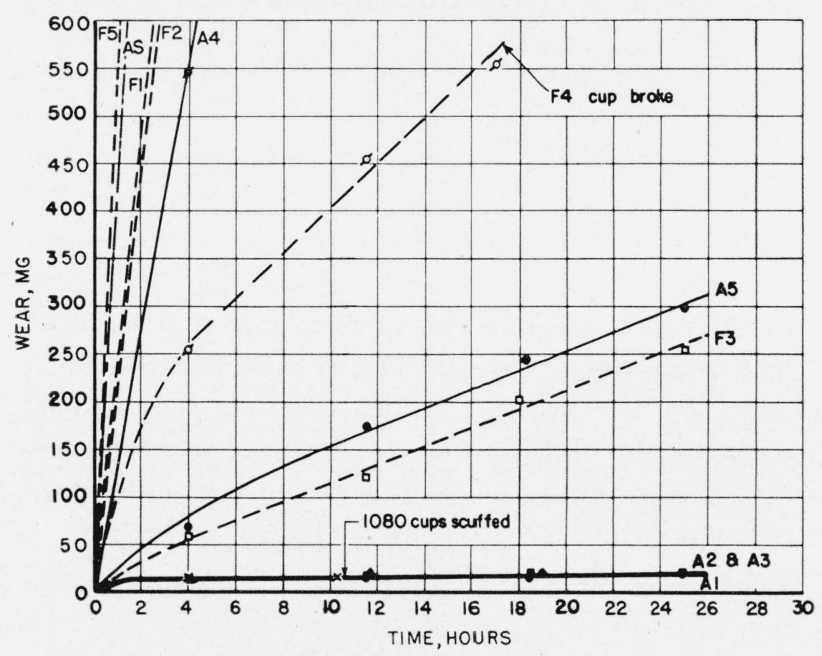

Figure 8. Wear versus time curves for all lubricants operating at $225-\mathrm{lb}$ load and $225^{\circ} \mathrm{F}$.

These effects are summarized in table 1, which gives the values of the rate of wear expressed in milligrams per hour for each lubricant at each operating condition. These values are based on the slopes of the straight portion of the curves. Values for the tests at $225^{\circ} \mathrm{F}$ are also shown in figure 9 , from which it will be noted that when operating at this temperature and the 90-lb load the rate of wear with all the lubricants is relatively low. At the 135-lb load, however, the wear with the lead-soap active-sulfur lubricant and two of the Federal specification lubricants has definitely increased. These differences become accentuated at the two higher loads. At $180 \mathrm{lb}$, the wear was excessive with the active-sulfur lubricant and with four of the Federal specification lubricants. At $225 \mathrm{lb}$, the wear was relatively low with three Army specification lubricants, moderate with one Army and one Federal lubricant, excessive with four Federal, one Army, and the active-sulfur lubricant, and scuffing occurred with the mineral oil.

Duplicate tests were not made with all of the lubricants under all operating conditions. However, the results of check tests under some conditions are given in parenthesis in table 1. These indicate that the results are reproducible within practicable limits. 
Table 1. Summary of wear data

\begin{tabular}{|c|c|c|c|c|c|}
\hline \multirow{3}{*}{ Lubricant } & \multicolumn{5}{|c|}{ Rate of wear after run-in period, $\mathrm{mg} / \mathrm{hr}$, at- } \\
\hline & \multicolumn{4}{|c|}{$225^{\circ} \mathrm{F}$} & \multirow{2}{*}{$\frac{250^{\circ} \mathrm{F}}{180 \mathrm{lb}}$} \\
\hline & $90 \mathrm{lb}$ & $135 \mathrm{lb}$ & $180 \mathrm{lb}$ & $225 \mathrm{lb}$ & \\
\hline $1080 \ldots$ & $0.2(0.1)$ & $0.1(0.1)$ & $0.2(0.2)$ & Scuffed & 0.2 \\
\hline AS ............ & .2 & 25 & 120 & 440 & 400 \\
\hline A1 ..... & .1 & 0.2 & 0.3 & 0.2 & 0.2 \\
\hline$A 2 \ldots$ & .4 & .4 & .3 & .2 & .4 \\
\hline A3 .... & .6 & .7 & .8 & .2 & .6 \\
\hline 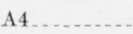 & $.2(0.3)$ & .7 & .2 & 140 & .3 \\
\hline A5 ......... & 1 & .4 & $3.7(4.7)$ & 9.9 & 9.0 \\
\hline $\mathrm{F} 1 \ldots$ & .2 & 0.2 & 260 & 240 & 260 \\
\hline $\mathrm{F} 2 \ldots$ & .2 & 1.3 & 190 & 215 & 200 \\
\hline F3 . . & 1.0 & $4.6(2.5)$ & 5.2 & 9.7 & 4.5 \\
\hline $\mathrm{F} 4$ & 0.6 & 6.7 & $21(24)$ & a 24 & 10 \\
\hline F5 .... & .1 & 0.3 & 220 & 560 & 500 \\
\hline
\end{tabular}

a Top cup broke: first test at $17 \mathrm{hr}$; check at $716 \mathrm{~h} \mathrm{hr}$.

Although wear data with hypoid gears are not available for a direct comparison, it is believed that these results are in reasonable agreement with the known service performance with these lubricants. The wear with the mineral oil was low up to the point where it would not carry the load, whereas with the lead-soap active-sulfur lubricant (which will carry a high shock load) the wear was relatively high at all but the lightest load.
Values of the rate of wear obtained in the tests with all the lubricants operating at the $180-\mathrm{lb}$ load and $250^{\circ} \mathrm{F}$ are also given in table 1 . These data show no marked difference from the data obtained at $225^{\circ} \mathrm{F}$ with the same load.

\section{Surface Roughness Data}

In most of the tests, Profilometer readings of the surface roughness of the test cups were obtained at intervals during the test run. Typical data showing the changes in surface roughness that took place during the test runs are given in figures 10 and 11 . In the figures, the average values of the roughness of the cups in microinches (rms) is plotted against the time in hours when operating with some of the lubricants at $225^{\circ} \mathrm{F}$ and with loads of 135 and $180 \mathrm{lb}$, respectively. In all of these tests, the original roughness of the cups averaged about 28 microinches. From a comparison of these figures with the wear data given in figures 6 and 7 , it will be noted that in the tests where the rate of wear was relatively low the roughness decreased in the run-in period and tended to level off in a range between 10 and 20 microinches. As the rate of wear increased, there was a trend for the roughness to increase. This was especially noticeable in cases of excessive wear
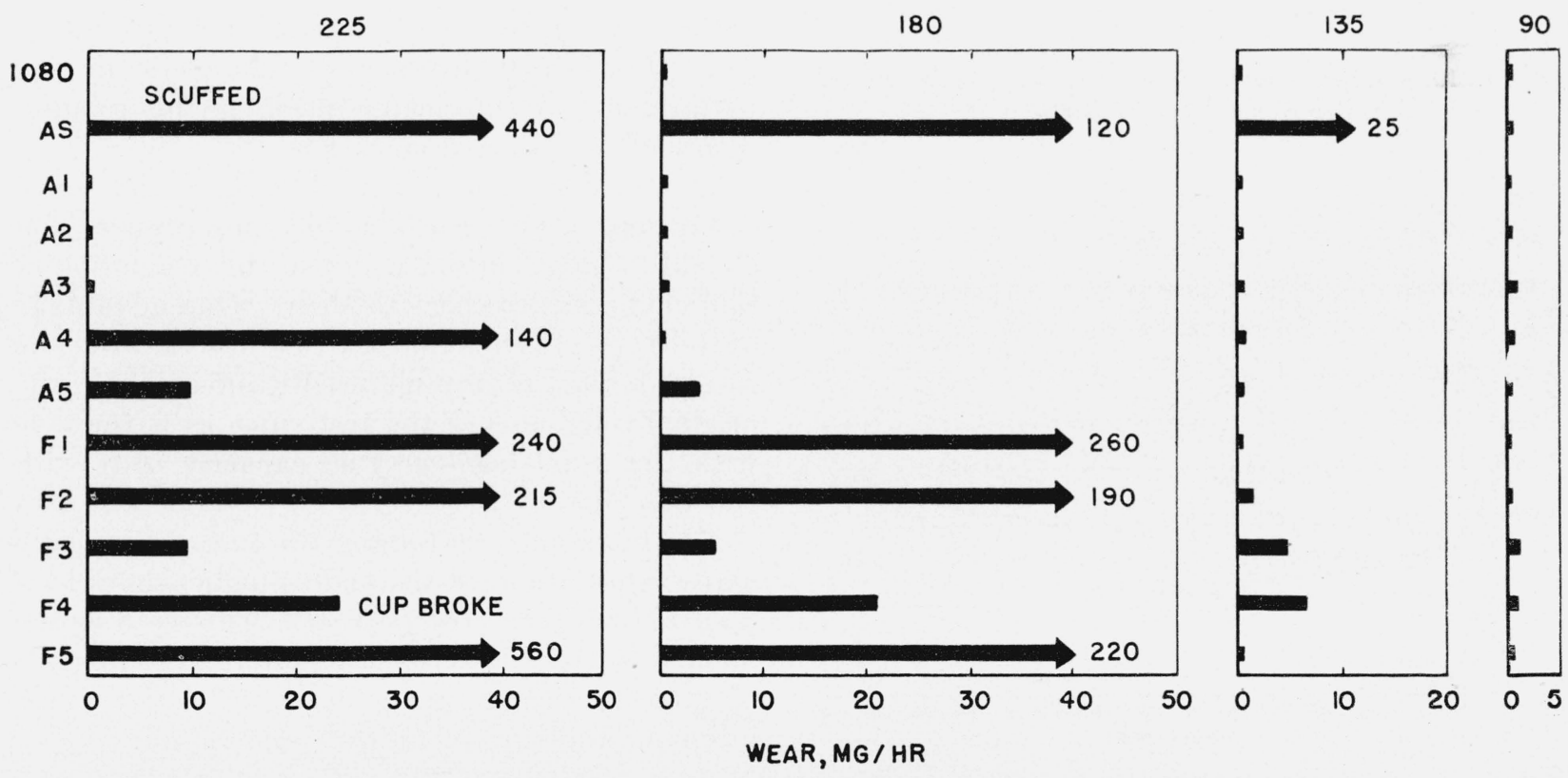

Figure 9. Rate of wear at $225^{\circ} \mathrm{F}$ for all lubricants at various loads. 
where there was definite "ridging" of the cups, which in some cases was beyond the range of the Profilometer.

Some study was also made of the effect of the original surface roughness of the cups on the rate of wear. Data obtained in tests with the mineral oil and one of the Army specification lubricants operating at $225^{\circ} \mathrm{F}$ and 135 -lb load, using cups with original roughnesses of 14,28 , and 35 microinches (rms), are given in figure 12. Surface roughness versus time curves are shown in the upper part of the figure. These indicate that the net result of operation was to bring the roughness of the cups fairly close together. The wear versus time curves for these tests are given in the lower part of the figure. From these it will be noted that while the run-in wear tended to increase with increase in roughness, the final rate of wear was practically independent of original surface roughness over the range covered. This is of considerable importance in tests of this kind in that

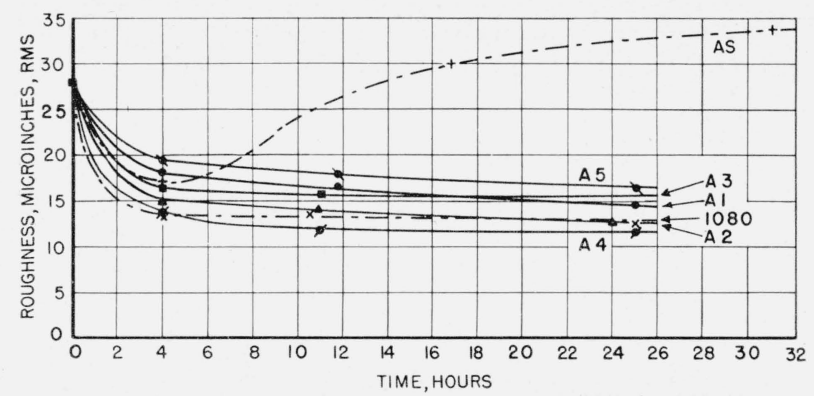

Figure 10. Surface roughness versus time curves for various lubricants operating at 135-lb load and $225^{\circ} \mathrm{F}$.

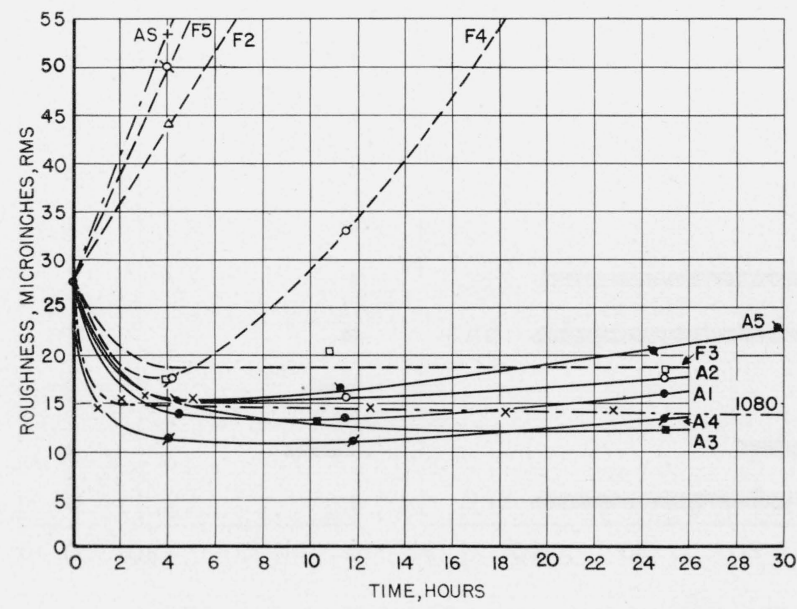

Figure 11. Surface roughness versus time curves for various lubricants operating at $180-\mathrm{lb}$ load and $225^{\circ} \mathrm{F}$. comparable data may be obtained with reasonable tolerances in the surface roughness of the cups.
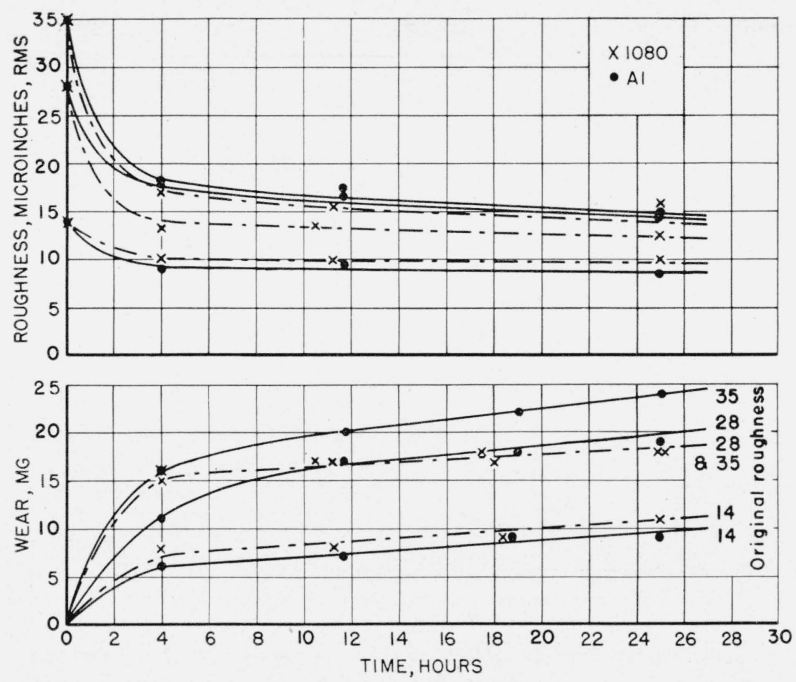

Figure 12. Curves for two lubricants showing surface roughness and wear as functions of time for three values of original surface roughness when operating at 135-lb load and $225^{\circ} \mathrm{F}$.

\section{Conclusion}

The results of these tests indicate that this method of operating the SAE machine provides a sensitive measure of the rate of wear obtained with various commercial gear lubricants under conditions simulating high torque and low speed in automotive gears. The data are of interest in that they show significant differences in the performance of lubricants meeting the requirements of the same specification.

The evidence of a run-in wear under some conditions is of considerable importance and should be taken into account in the evaluation of lubricants with respect to wear. One advantage of this type of test is that the rate of wear after the run-in period is not materially affected by the original roughness of the test cups, as is the case with the usual load-carrying capacity tests with this machine.

The lubricants containing the more chemically active additives for withstanding higher shock load tend to show the greater wear. This is in agreement with the known service performance of some of these lubricants, particularly the active-sulfur lubricant and the nonadditive mineral oil.

Washington, September 27, 1948 